\section{Use of Manganese in RT-PCR Eliminates PCR Artifacts Resulting from DNase I Digestion}

BioTechniques 22:1128-1132 (June 1997)

\begin{abstract}
The precise quantification of rare $m R N A$ copies from intronless genes by reverse transcription polymerase chain reaction (RT-PCR) requires the complete removal of genomic DNA because discrimination of cDNA and DNA amplification products by differing sizes of PCR products is not possible. Elimination of DNA is achieved by treating the RNA sample with RNase-free DNase I before RT-PCR. The lack of a PCR product from DNase-treated RNA samples before RT is usually accepted as a proof of efficient DNA destruction. However, this may vary depending on the metal cofactor used in the DNase I cleavage. Treating DNA-contaminated RNA samples with DNase I and magnesium as a cofactor creates a negative PCR control after digestion without further RT. Paradoxically, after additional RT-PCR, the original intron-containing DNA fragment size may be produced again. In the presence of manganese as cofactor, RT-created DNA fragments do not appear. This is because in the presence of manganese, DNase I cleaves both DNA strands at approximately the same site, yielding DNA fragments that are blunt-ended or that have protruding termini of only one or two nucleotides in length. However, overlapping fragments with the potential to recombine are created by DNase digestion with magnesium as cofactor. Because one cannot differentiate between a PCR signal produced by RNA and one produced by recombined DNA after DNase I digestion and $R T$, all such DNase I assays should be performed with manganese instead of magnesium.
\end{abstract}

\section{INTRODUCTION}

Frequently used methods for preparing RNA $(1,4)$ cannot guarantee that the RNA sample is free of contaminating genomic DNA. Even a small amount of DNA contamination of RNA samples will influence the reliability of RNA quantification in reverse transcription polymerase chain reaction (RT-PCR) because of the incalculable competition of DNA. For the investigation of intron-containing genes, junction primers (5) for the selective amplification of the spliced transcripts may solve the problem of DNA contamination. However, investigation of transcripts of intronless genes shows that cDNA and DNA amplicons are of identical length. In these cases, it is necessary to treat the RNA sample with RNase-free DNase I before performing RT-PCR $(2,7)$.

The essential requirement for DNase I activity is the presence of divalent metal ions in the reaction mixture. The magnesium optimum concentration $(5.2 \mathrm{mM})$ is approximately one order of magnitude greater than that of manganese $(0.66 \mathrm{mM})$. At optimal concentration, activity of DNase I with manganese doubles that of DNase I with magnesium (3). The mechanism of DNA cleavage by DNase I largely depends on which metal cofactor is used in the reaction. In the presence of magnesium, DNase I cleaves each DNA strand independently, and the cleavage sites are distributed in a statistically random manner (6). In the presence of manganese, DNase I cleaves both DNA strands at approximately the same site, creating fragments of DNA that are blunt-ended or have protruding termini of one or two nucleotides.

We demonstrate that the use of a buffer containing magnesium for DNase I cleavage of DNA contaminants in RNA samples leads to DNA artifacts after RT-PCR. Although all biochemical contributors use a buffer containing magnesium for DNase I cleavage, a manganese buffer is of practical benefit for RT-PCR assays.

\section{MATERIALS AND METHODS}

\section{RNA Isolation}

RNA was extracted from nitrogenfrozen human heart tissues. The samples were homogenized, the total cellular RNA isolated with the use of the acid guanidinium thiocyanate/phenol/ chloroform (RNAzol $^{\mathrm{TM}} \mathrm{B}$; Tel-Test
"B", Friendswood, TX, USA) extraction method (1) and precipitated by centrifugation with a Model 5402 Centrifuge (Eppendorf, Hamburg, Germany) at $4{ }^{\circ} \mathrm{C}$ with $100 \%$ isopropanol. The pellets were washed twice with $75 \%$ ethanol, dried and resuspended in diethyl pyrocarbonate (DEPC)-treated water. RNA samples were tested in PCR to demonstrate possible DNA contamination.

\section{DNase I Cleavage}

RNA $(1 \mu \mathrm{g})$ was treated with $2 \mathrm{U}$ DNase I (Boehringer Mannheim, Mannheim, Germany) for $10 \mathrm{~min}$ at $37^{\circ} \mathrm{C}$ in the presence of $40 \mathrm{U}$ RNasin ${ }^{\circledR}$ Ribonuclease Inhibitor (Promega, Heidelberg, Germany) per $\mu$ g RNA. Final concentration of magnesium and manganese was $1 \mathrm{mM}$. After DNase I digestion, the aliquot was heated to $90^{\circ} \mathrm{C}$ for $5 \mathrm{~min}$.

\section{Reverse Transcription}

Ninety percent of the DNase I-digested RNA sample was used for the RT reaction; the rest served as a PCR control. Up to $1 \mu \mathrm{g}$ of DNase I-treated RNA was incubated with $100 \mathrm{ng}$ random hexanucleotides for $10 \mathrm{~min}$ at $70^{\circ} \mathrm{C}$ and stored at $4^{\circ} \mathrm{C}$. A mixture containing 100 U SUPERSCRIPT ${ }^{\mathrm{TM}}$ Maloney murine leukemia virus (M-MLV) Reverse Transcriptase (Life Technologies, Berlin, Germany), $3 \mathrm{mM} \mathrm{MgCl} 2,50$ $\mathrm{mM}$ Tris-HCl, $\mathrm{pH} 8.3,75 \mathrm{mM} \mathrm{KCl}, 10$ $\mathrm{mM}$ dithiothreitol (DTT), $0.5 \mathrm{mM}$ dNTPs and 40 U RNasin was added, and the sample was then incubated at $42^{\circ} \mathrm{C}$ for $50 \mathrm{~min}$. The reaction was suspended at $95^{\circ} \mathrm{C}$ for $5 \mathrm{~min}$.

\section{PCR}

An intron-overspanning primer system within the pyruvate dehydrogenase $(P D H)$ gene (forward primer: 5' GGT ATG GAT GAG GAC CTG GA 3', reverse primer: 5' CTT CCA CAG CCC TCG ACT AA 3') was used to create an amplicon of $185 \mathrm{bp}$ at the DNA level and $103 \mathrm{bp}$ at the cDNA level. In prior experiments, we had demonstrated that there are no pseudogenes extant at this $P D H$ gene region. Larger amplicons (538 bp) were created using primers 
specific to the intronless angiotensin II type $1(A T 1)$ receptor gene (forward primer: 5' CCT TCG ACG CAC AAT GCT TG 3', reverse primer: 5' ATG ATT GTC CCA AAG CTG GA 3'). PCR was performed using $50 \mathrm{ng}$ template in a $25-\mu \mathrm{L}$ assay mixture (denaturation at $95^{\circ} \mathrm{C}$ for $5 \mathrm{~min}$, followed by 40 cycles of: denaturation at $95^{\circ} \mathrm{C}$ for $45 \mathrm{~s}$, annealing at $60^{\circ} \mathrm{C}$ for $60 \mathrm{~s}$ and extension at $72^{\circ} \mathrm{C}$ for $45 \mathrm{~s}$; followed by a final extension at $72^{\circ} \mathrm{C}$ for $5 \mathrm{~min} ; 8$ pmol of each primer, $50 \mathrm{mM} \mathrm{KCl}, 10$ $\mathrm{mM}$ Tris- $\mathrm{HCl}, \mathrm{pH} 8.3,2.5 \mathrm{mM} \mathrm{MgCl} 2$, $100 \mu \mathrm{M}$ dNTPs, 1.0 U Taq DNA Poly- merase [Perkin-Elmer GmbH, Überlingen, Germany]) in a GeneAmp ${ }^{\circledR}$ PCR System 9600 Thermal Cycler (PerkinElmer $\mathrm{GmbH})$. The PCR product (6 $\mu \mathrm{L})$ was analyzed in an ethidium bromide-stained NuSieve ${ }^{\circledR}$ 3:1 agarose gel (FMC BioProducts, Hess.-Oldendorf, Germany).

Southern blots were carried out according to standard protocols (5). Minimum blotting time was $6 \mathrm{~h}$. For hybridization, the blotted and crosslinked, positively charged nylon membranes (Boehringer Mannheim) were incubated with PCR-synthesized

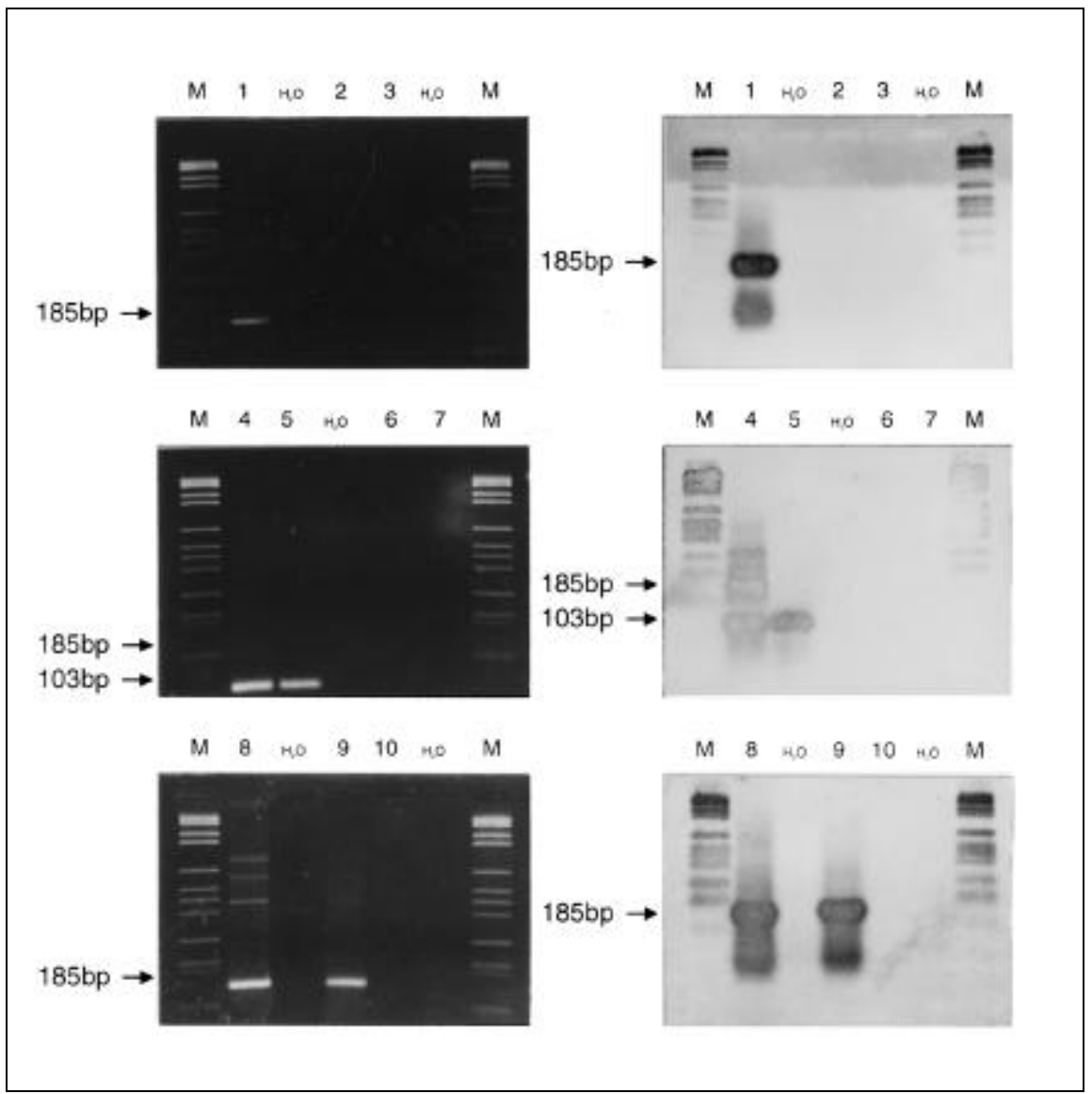

Figure 1. Amplification results of an RNA preparation aliquot with the PDH primer system (yielding a 103-bp cDNA and 185-bp DNA fragment) in agarose gels (left) as well as the corresponding Southern blots (right). $\mathrm{M}$ denotes the DNA size marker (Boehringer VI marker; Boehringer Mannheim), $\mathrm{H}_{2} \mathrm{O}$ for negative amplification controls (without DNA). Details for the reaction conditions and the probe sequences are given in Materials and Methods. Lane 1: direct amplification of $50 \mathrm{ng}$ purified RNA; the 185-bp PDH DNA fragment indicates contaminating genomic DNA. Lanes 2 and 3: PCR amplification of $50 \mathrm{ng}$ purified RNA from the same aliquot as lane 1 after cleavage with DNase I but no RT; lane 2: $1 \mathrm{mM} \mathrm{Mg}^{2+}$ buffer; lane 3: $1 \mathrm{mM} \mathrm{Mn}^{2+}$ buffer. No PCR products are demonstrable as proof of effective DNA digestion. Lanes 4 and 5: aliquot from the same sample used in lanes 2 and 3 but now followed by RT (M-MLV); lane 4: $1 \mathrm{mM} \mathrm{Mg}^{2+}$ buffer; the 103-bp cDNA fragment and, surprisingly, the 185-bp DNA fragment appear; lane 5: $1 \mathrm{mM} \mathrm{Mn}^{2+}$ buffer; exclusively the 103-bp cDNA fragment appears. Lanes 6 and 7: negative controls to document that all chemicals were free of contaminations. Lane 8: $50 \mathrm{ng}$ DNA as a positive control (185-bp amplicon). Lane 9: $50 \mathrm{ng}$ DNA, DNase $\mathrm{I} / \mathrm{Mg}^{2+}$ digest (185bp fragment). Lane 10: $50 \mathrm{ng}$ DNA, DNase I/Mn ${ }^{2+}$ digest (no PCR product). 


\section{Short Technical Reports}

digoxigenin (Dig)-11-dUTP-labeled probes in a $5 \times$ standard saline citrate (SSC) hybridization buffer $(0.75 \mathrm{M}$ $\mathrm{NaCl}, 0.075$ sodium citrate, $\mathrm{pH} 7.0)$ for at least $6 \mathrm{~h}$ at $62^{\circ} \mathrm{C}$. After washing twice at room temperature for $5 \mathrm{~min}$ in $2 \times$ SSC, $0.1 \%$ sodium dodecyl sulfate (SDS) and twice for $15 \mathrm{~min}$ at $62^{\circ} \mathrm{C}$ in $0.2 \times \mathrm{SSC}, 0.1 \%$ SDS, chromogen detection was performed as described in Rolfs et al. (5).

Using primer pairs located within the amplified $\mathrm{PDH}$ region (foward primer: 5' TGC TTG GAG AAG AAG TTG CC 3', reverse primer: 5' TCT GGG GGT AAC AGT GAC CT 3’), a 94-bp amplicon was amplified directly from control DNA. After examination in a preparative $1 \%$ NuSieve GTG $^{\circledR}$ agarose gel (FMC BioProducts), the amplicon was cut from the gel, and 5 $\mu \mathrm{L}$ of melted agarose were re-amplified directly using the same primers as given above with a dNTP-labeling mixture in which $35 \%$ of dTTP was replaced by Dig dUTP. Ensure that no contamination with external amplicons takes place during probe synthesis. This probe was used in the hybridization step without any further purification. All primers were synthesized by TibMolBiol (Berlin, Germany).

\section{RESULTS}

RNA samples extracted with acid guanidinium thiocyanate/phenol/chloroform (1) without subsequent DNase I treatment all demonstrated, as clear evidence of DNA contamination, more or less intense PDH-specific DNA signals in direct PCR testing (Figure 1, lane 1). After treating the RNA aliquot with DNase I using either magnesium or manganese as cofactors, no further DNA signal (185-bp fragment) was apparent in the PCR (Figure 1, lanes 2 and 3). Using an aliquot digested with a DNase I/magnesium buffer for RTPCR, the specific 103-bp cDNA fragment was observed, but surprisingly, the DNA-specific, 185-bp amplicon also appeared (Figure 1, lane 4). In contrast, when the DNase I cleavage was performed with the manganese buffer followed by RT-PCR, only the 103-bp cDNA amplicon was detected (Figure 1, lane 5).
The higher efficiency of DNA cleavage using manganese as a cofactor for DNase I was apparent when $1 \mu \mathrm{g}$ genomic DNA was treated with DNase I and subsequently amplified. Only samples digested with a DNase I/magnesium buffer still created amplicons (Figure 1, lane 9), whereas samples treated with DNase I/manganese buffer were free of DNA (Figure 1, lane 10). To verify that the artifact could not be overcome by simply adding more DNase enzyme to the magnesium buffer, we cleaved $2 \mu \mathrm{g}$ RNA in the presence of magnesium with 2, 4, 8 and 16 U DNase I (Figure 2). Though every chosen DNase I concentration was able to eliminate contaminating genomic DNA before RT, none of them prevented reappearance of DNA after RT.

To evaluate how this phenomenon affects the quantification of mRNA from intronless genes, we amplified the 538-bp AT1 fragment after treatment with varying amounts of DNase I enzyme and different cleavage periods $\left(10,20\right.$ and $\left.30 \mathrm{~min}, 37^{\circ} \mathrm{C}\right)$ in a magnesium buffer. The AT1-specific signal decreased depending on the amount of

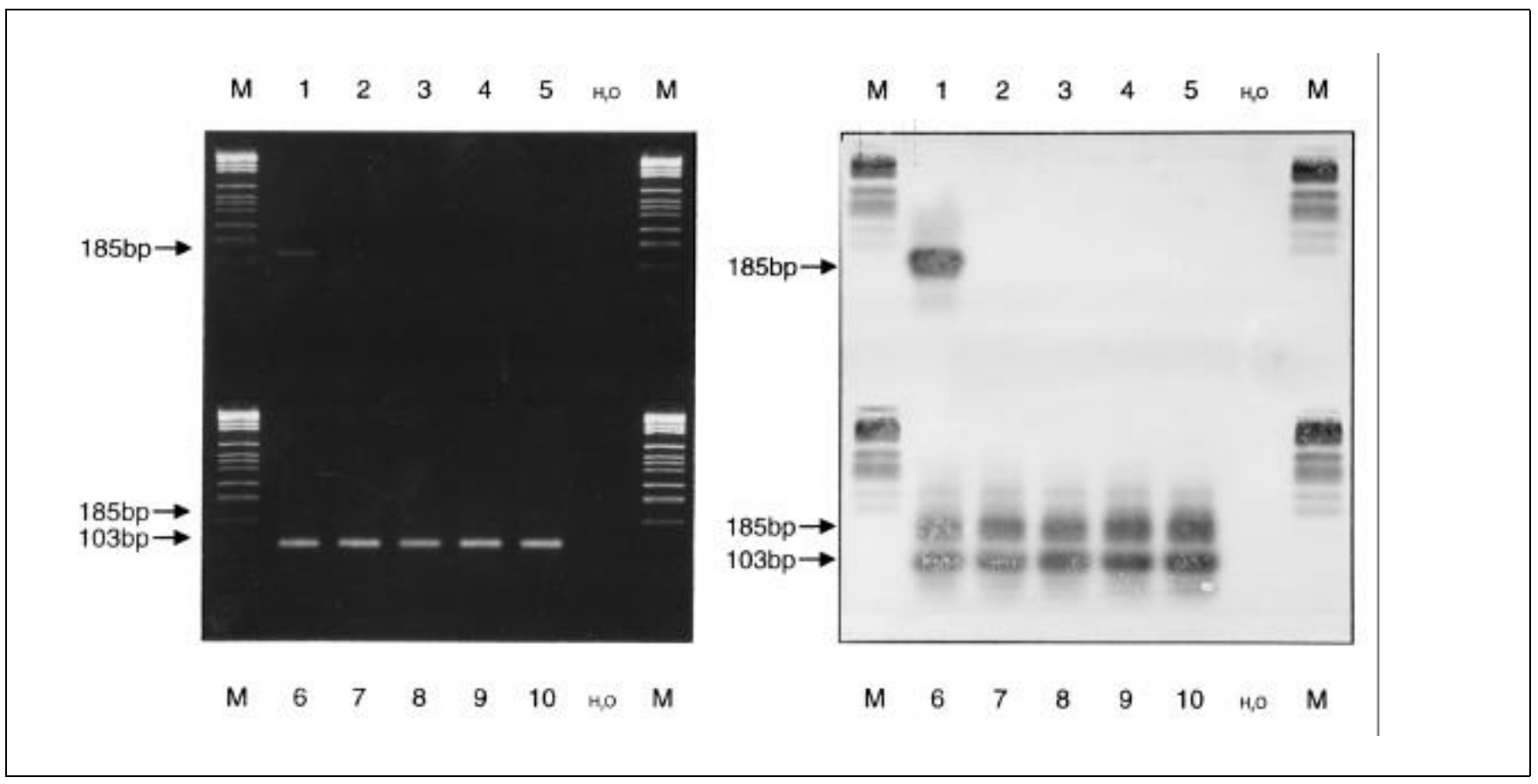

Figure 2. Influence of DNase I concentration on the DNA-generated artifact in DNase/Mg2+ buffers. $2 \mu \mathrm{g}$ RNA were incubated with $0,2,4,8$ and $16 \mathrm{U}$ DNase I in a $\mathrm{Mg}^{2+}$ buffer. Aliquots were PCR-amplified with the PDH primer system before and after RT. The figure includes agarose gel and corresponding Southern blot. $\mathrm{M}$ denotes the DNA size marker (Boehringer VI marker), $\mathrm{H}_{2} \mathrm{O}$ for negative amplification controls (without DNA). Though adding increasing amounts of DNase I enzyme in DNase/ $\mathrm{Mg}^{2+}$ buffer could eliminate contaminating DNA (lane 1: digestion with 0 U DNase I resulting in 185-bp PCR product; lanes 2-5: digestion with 2, 4, 8 and $16 \mathrm{U}$ DNase I; no amplification products), no enzyme concentration could avoid the DNA-generated artifact after RT of the samples (lanes 6-10: corresponding to 0, 2, 4, 8 and 16 U DNase-treated RNA after RT resulting in 103-bp cDNA and 185-bp PCR products). 
enzyme available and the incubation time, indicating that part of the signal was due to contaminating DNA. In contrast, the levels of the 103-bp PDH cDNA fragment, an indicator of RNA amplification, remained unchanged in these samples.

To prove that DNA signals observed in the RT-PCR after DNase I/magnesium treatment were caused by the enzymatic properties of the M-MLV Reverse Transcriptase or Taq DNA polymerase, we repeated all experiments with one important modification: a pseudo-RT assay was performed without M-MLV enzyme. Under these conditions, no additional fragment of similar size was seen in the pseudo-RTPCR when the DNase I digestion was performed in the presence of magnesium.

\section{DISCUSSION}

We describe the phenomenon that PCR of a DNase I/magnesium buffertreated aliquot showing no DNA fragments without preceding RT may create DNA fragments when an additional $\mathrm{RT}$ reaction is performed. The phenomenon is probably based on the properties of DNases with regard to the metals that are chosen as cofactors in cleavage reactions (3). The enzymatic degradation of double-stranded DNA can occur in a "double-hit" mechanism in which both strands are cleaved during one encounter with the enzyme, or by a "single-hit" mechanism in which the enzyme cleaves only one strand per encounter, thus creating partially overlapping plus and minus strands. These overlapping strands can reassociate after denaturation and may create successively growing fragments to full length in a following PCR if an enzyme that possesses polymerase activity is added.

Applying these findings to our results, we suggest: $(i)$ in the presence of magnesium, DNase I cleaves each DNA strand independently, and the cleavage sites are statistically randomly distributed; (ii) during the inactivation of the DNase I at $90^{\circ} \mathrm{C}$, the partially overlapping fragments denature but anneal again and reassociate in the RT assay; and (iii) during the RT assay, the M-MLV Reverse Transcriptase elongates the partially overlapping frag- ments because of its $5^{\prime}-3^{\prime}$ DNA polymerase activity, thereby reducing the numbers of nicks and increasing the likelihood that these fragments will reanneal also in the PCR and create DNA-generated fragments. The benefit of manganese in DNase I cleavage is probably based on both altered cleavage mechanism and enhanced activity of the enzyme (3), creating shorter DNA fragments with reduced likelihood for reassociation.

However, since we were not able to demonstrate the DNA artifact in magnesium buffer using only M-MLV reaction conditions without the enzyme followed by a standard PCR, M-MLV enzyme is essential for the recreation of DNA-size fragments in the following PCR. Further experiments must be done to reveal whether a yet unknown enzymatic property of the M-MLV enzyme that is not given for Taq DNA polymerase or simply reaction conditions and temperatures in either RT or PCR contribute to the rising of DNA artifacts in RT-PCR after DNase I digestion with magnesium buffers.

In summary, for RT-PCR assays in which DNase I cleavage is required to remove contaminating DNA, it is essential to perform the DNase I digestion with manganese as the cofactor.

\section{REFERENCES}

1.Chomczynski, P. and N. Sacchi. 1987. Single-step method of RNA isolation by acid guanidinium thiocyanate-phenol-chloroform extraction. Anal. Biochem. 162:156-159.

2.Grillo, M. and F.L. Margolis. 1990. Use of reverse transcriptase polymerase chain reaction to monitor expression of intronless genes. BioTechniques 9:262-268.

3.Melgar, E. and D.A. Goldthwait. 1968. Deoxyribonucleic acid nucleases. J. Biol. Chem. 243:4409-4416.

4.Rappolee, D.A., A. Wang, D. Mark and Z. Werb. 1989. Novel method for studying mRNA phenotypes in single or small numbers of cells. J. Cell. Biochem. 39:1-11.

5.Rolfs, A., I. Schuller, U. Finckh and I. Weber-Rolfs. 1992. PCR: Clinical Diagnostics and Research, p. 117-124. Springer Verlag, Heidelberg, New York.

6.Sambrook, J., E.F. Fritsch and T. Maniatis. 1989. Molecular Cloning: A Laboratory Manual, 2nd ed. Cold Spring Harbor Laboratory Press, Cold Spring Harbor, NY.

7.Ziegler, B.L., C. Lamping, S. Thoma and C.A. Thomas. 1992. Single-cell cDNA-PCR: removal of contaminating genomic DNA from total RNA using immobilized DNase I. BioTechniques 13:726-729.

The authors wish to thank Heike Kallisch, Petra Bartsch, Britta Hannak and Claudia Bauer for their excellent technical help. Address correspondence to V. RegitzZagrosek, Deutsches Herzzentrum Berlin, Augustenburger Platz 1, 13353 Berlin, Germany.Internet: regitz@ukrv.de

Received 13 December 1994; accepted 18 November 1996.

P. Bauer, A. Rolfs' ${ }^{1}$, V. Regitz-
Zagrosek, A. Hildebrandt ${ }^{2}$
and E. Fleck
Humboldt Universität and
Deutsches Herzzentrum
Berlin
${ }^{1}$ Universität Rostock
Rostock

